\title{
Measuring the melt pool size in a wire arc additive manufacturing process using a high dynamic range two-colored pyrometric camera
}

\author{
C. Halisch ${ }^{1} \cdot$ T. Radel $^{1} \cdot$ D. Tyralla ${ }^{1} \cdot$ T. Seefeld $^{1}$
}

Received: 9 January 2020 / Accepted: 16 March 2020 / Published online: 8 April 2020

(C) The Author(s) 2020

\begin{abstract}
Control of the melt pool size is necessary to achieve more homogenous material properties in wire arc additive manufacturing (WAAM). The melt pool size can be measured by camera imaging or temperature field measurement. The paper aims to investigate the feasibility of using a high dynamic range two-colored pyrometric camera (Pyrocam) for melt pool size measurement in a gas metal arc welding-based WAAM process. A set of band-pass filters is identified using spectroscopy analysis to reduce the optical arc emission while the melt pool remains visible. The fusion line is identified in temperature field images, the melt pool size is measured by an automated algorithm, and the results are compared with high-speed camera images. A possible correlation between melt pool size and the grain size is examined.
\end{abstract}

Keywords Additive manufacturing $\cdot$ DED $\cdot$ GMAW $\cdot$ High-speed camera $\cdot$ Microstructure $\cdot$ Temperature field $\cdot$ Ti6Al4V

\section{Introduction}

In recent years direct energy deposition (DED) processes have become more important in the industry. High deposition rates can be achieved, enabling a fast production of large parts. There is a market for a fast production of spare parts on demand. Especially, the aerospace industry shows high interest in the DED processes, because it allows a cheaper generation of the near net shape milling parts made of expensive alloys like Ti-6Al-4V.

There are different direct energy deposition processes. Gas metal arc welding (GMAW) provides the highest deposition rates with up to $5 \mathrm{~kg} / \mathrm{h}$ in comparison with the lower

Recommended for publication by International Institute of Welding (IIW) Commission I - Additive Manufacturing, Surfacing, and Thermal Cutting

This article is part of the Topical Collection on Additive Manufacturing Processes, Simulation and Inspection

Electronic supplementary material The online version of this article (https://doi.org/10.1007/s40194-020-00892-5) contains supplementary material, which is available to authorized users.

C. Halisch

halisch@bias.de

1 BIAS - Bremer Institut für angewandte Strahltechnik GmbH, Klagenfurter Str. 5, 28359 Bremen, Germany deposition rates of gas tungsten arc welding (GTAW) and plasma-based welding processes [1]. In arc additive manufacturing of Ti-6Al-4V, the main issues that researchers focus on are oxidation [2-4], residual stress [5], mechanical characterization $[6,7]$, and microstructural analysis [8-10].

Online monitoring of wire- and arc-based direct energy deposition processes is an issue of common interest. Xu et al. [11] present a general overview online monitoring possibilities and states that most of the welding defects are "are associated with thermal history" [11]. Wu et al. showed [12] the effects of the melt pool size onto mechanical properties. However, they did not measure the melt pool size, while Xiong et al. [13] used two vision sensors to measure bead geometry. Several approaches [14-16] use pyrometers, thermo couples, or thermal cameras to monitor the temperature dissipation.

A high dynamic range two-colored pyrometric camera shows promising potential as a comprehensive online monitoring tool. It measures a temperature field, and its vision channel enables the measurement of the bead geometry. It has been successfully applied in laser cladding [17] and laser gas metal arc hybrid welding [18]. It does not need to be calibrated for different materials, and in contrast to many IR thermal cameras, it can measure through a standard window glass.

The focus of this work is to prove the applicability of this camera as an online monitoring tool in a wire-based direct energy deposition process using GMAW as well as to investigate the influence of the melt pool size on the microstructure. 


\section{Materials and set-up}

\subsection{Material}

A Ti-6Al-4V welding wire with $1.2-\mathrm{mm}$ diameter was used. The chemical analysis according to the supplier is shown in Table 1 .

As base material, pickled Ti-6Al-4V plates with $200 \mathrm{~mm} \times$ $200 \mathrm{~mm} \times 10 \mathrm{~mm}$ were used. The chemical analysis of the base material is shown in Table 2 .

\subsection{Welding process}

The welding experiments were performed with a Gefertec Arc403 3D metal printing machine. This machine contains a Fronius TransPuls Synergic 4000 CMT R (cold metal transfer) power source, and the torch is mounted on a three-axis gantry system. The arc mode was CMT at a wire feed rate of $9.8 \mathrm{~m} /$ min, a nominal current of $179 \mathrm{~A}$, a nominal voltage of $16.6 \mathrm{~V}$, and the travel speed of $1.8 \mathrm{~m} / \mathrm{min}$. A mixture of $70 \%$ Helium and 30\% Argon was used as process gas with $161 / \mathrm{min}$ flow rate. The workpiece to contact tip distance was set to $15 \mathrm{~mm}$.

An argon chamber was used in order to prevent oxidation during processing. This chamber was filled with Argon 4.8 (minimum purity of $99.998 \%$ ). A flow rate of $50 \mathrm{l} / \mathrm{min}$ was applied for $6 \mathrm{~min}$ before welding to produce constant shielding gas conditions.

Samples with a width of $22 \mathrm{~mm}$, a length of $100 \mathrm{~mm}$, and a height of $35 \mathrm{~mm}$ were built. The welding head was oscillated with a meander motion (see Fig. 1). Between each layer, there was an inter-run delay time of $120 \mathrm{~s}$.

\subsection{Spectroscopy}

The optical emissions of the arc were measured using a Stellarnet Inc. Silver-Nova spectrometer. It measures in a wavelength range of 190-1100 nm with a resolution of $1 \mathrm{~nm}$ with a $25-\mu \mathrm{m}$ slit. A neutral density filter OD2 was used to tone down the arc emission. It uses a UV-enhanced CCD detector cooled by a TE Cooler. The measurement was carried out with a frequency of $33 \mathrm{~Hz}$ for $5 \mathrm{~s}$.

\subsection{High-speed camera imaging}

A Phantom VEO 410L high-speed camera operating at a sample rate of $6000 \mathrm{~Hz}$ was used for process observation with a

Table 1 Chemical analysis of the Ti-6Al-4V wire (source: Perryman data sheet)

\begin{tabular}{lllllllll}
\hline Element & $\mathrm{Ti}$ & $\mathrm{Al}$ & $\mathrm{V}$ & $\mathrm{Fe}$ & $\mathrm{O}_{2}$ & $\mathrm{Si}$ & $\mathrm{N}_{2}$ & $\mathrm{H}_{2}$ \\
\hline
\end{tabular}

$\begin{array}{lllllllll}\text { Content }(\% w t) & \text { Balance } & 6.39 & 3.96 & 0.18 & 0.16 & 0.011 & 0.007 & 0.003\end{array}$
Table 2 Chemical analysis of the Ti-6Al-4V base material (source: GAB Titan data sheet)

\begin{tabular}{lllllllll}
\hline Element & $\mathrm{Ti}$ & $\mathrm{Al}$ & $\mathrm{V}$ & $\mathrm{Fe}$ & $\mathrm{O}_{2}$ & $\mathrm{Si}$ & $\mathrm{N}_{2}$ & $\mathrm{H}_{2}$ \\
\hline Content (\%wt) & Balance & 6.20 & 4.08 & 0.17 & 0.17 & - & 0.01 & 0.002 \\
\hline
\end{tabular}

resolution of $832 \times 200$ pixels. For process illumination, a Cavitar Cavilux HF illumination laser operating at a wavelength of $810 \mathrm{~nm} \pm 10 \mathrm{~nm}$ was used synchronized to the camera. A band-pass filter with a transmissivity range of $800 \mathrm{~nm}$ $\pm 20 \mathrm{~nm}$ was attached to the camera.

\subsection{High dynamic range two-colored pyrometric camera imaging}

The measurement of the temperature field was carried out using an IMS Chips Pyrocam high dynamic range quotient pyrometric camera with a resolution of $640 \times 480$ pixels. It measures in the wavelength area of $400-750 \mathrm{~nm}$ and is calibrated for temperatures between 600 and $1900^{\circ} \mathrm{C}$. The sample rate was set to $20 \mathrm{~Hz}$. A long pass filter $(625 \mathrm{~nm})$, a filter short pass filter $(750 \mathrm{~nm})$, and a neutral density filter OD2 were selected and calibrated with the optical system.

\subsection{Metallography}

Cross and top view sections have been taken after welding. The sections were ground, polished, and etched. The etchant used was a Kroll etchant.

\section{Methodology, results, and discussion}

\subsection{Spectroscopy}

The melt viscosity on Ti-6Al-4V needs to be reduced to guarantee build-up geometry and to avoid lack of fusion. Thus, to increase the melt pool temperature either the welding current/ voltage can be increased or the process gas needs to be changed from the regularly used pure argon. Since the electrical parameters are already at the top of the power limit of power source using pure CMT, it is necessary to change the gas mixture. An argon + helium mixture increases the melt pool temperature and has shown the best welding results.

The optical emission of the arc interferes with the pyrometric measurement. For each gas mixture, the optical arc emission is different. It is necessary to find an optimal wavelength range, where the optical arc emission is minimal. For that reason, a spectroscopy measurement using different gases (or gas mixes) was conducted (Fig. 2).

The level of intensity counts of pure Argon is slightly higher compared with $70 \% \mathrm{He}+30 \% \mathrm{Ar}$, but the general trend 
Fig. 1 Set-up and schematic of the meander motion

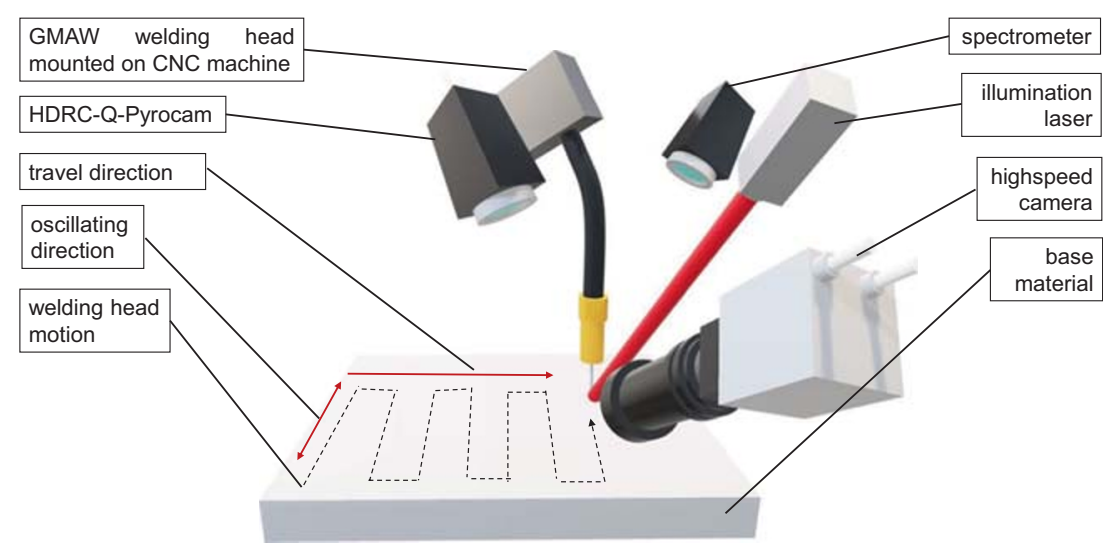

Selected pictures of the high-speed monitoring are shown in Fig. 4. At respective weld times the melt pool dimension is measured.

It is commonly known that the melt pool size increases at the beginning of the welding process until it reaches a steady size. That increase is evident in the results of the melt pool dimensions shown in Table 3.

The melt pool dimensions between high-speed camera imaging and Pyrocam imaging are compared in the starting phase of the welding process, because the steady phase would only provide one constant value.

\subsection{High dynamic range two-colored pyrometric camera imaging}

The methodology to analyze the temperature field measurement data is shown in Fig. 5. In the temperature field image, an orange square is automatically generated marking the maximum dimensions of the area that has a temperature above $1650{ }^{\circ} \mathrm{C}$, corresponding to the melting point of Ti6Al4V. The melt pool area is searched for within the region of interest (ROI) marked by the green square. The dimensions of the ROI are limited by areas of high optical arc emissions or their back reflections. The right side of the ROI is placed directly onto the center on the wire. To measure the melt pool dimension, the vertical distance $(X)$ between the melt pool boundary is analyzed.
Fig. 2 Spectroscopy measurement of different process gases

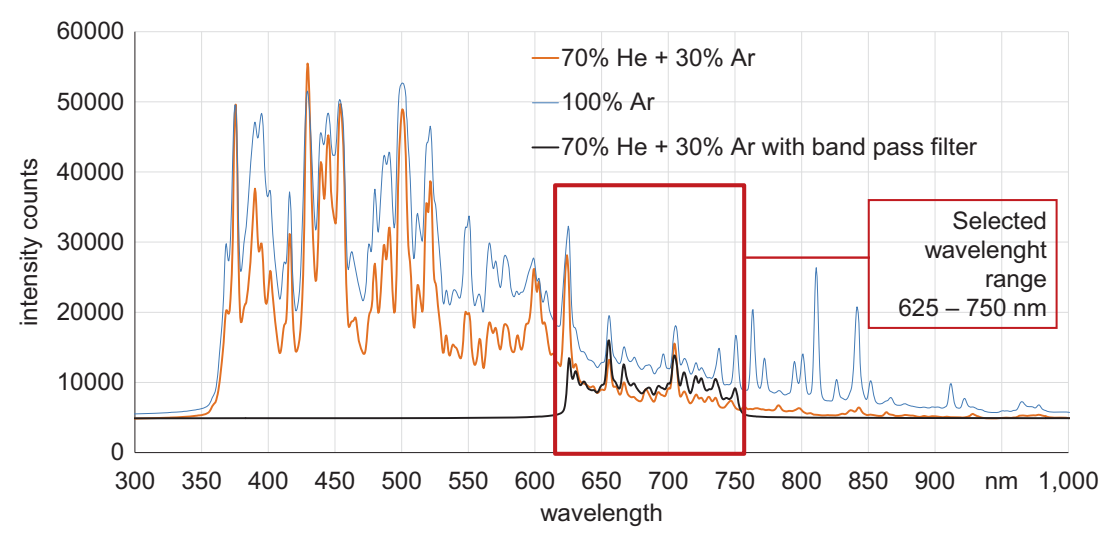


Fig. 3 Principle of measuring the melt pool dimension using a highspeed camera

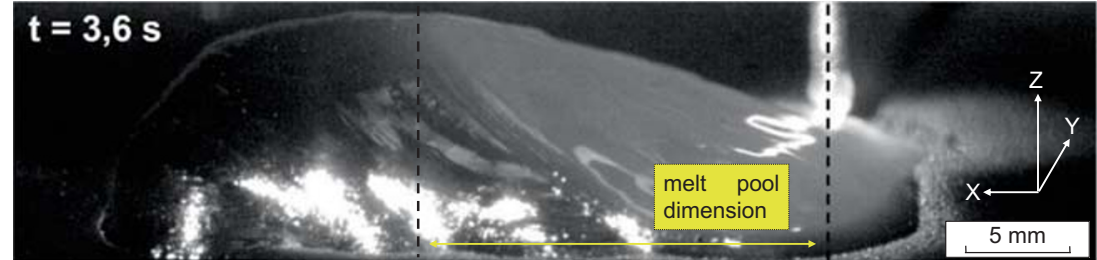

The measured melt pool dimensions using the Pyrocam in correlation to weld time in the first layer and the melt pool dimensions measured using the high-speed camera are shown in Fig. 6. In analogy to the high-speed camera imaging, a ruler was used to calibrate the distance measurement. Prior to welding, the ruler was placed on the substrate material; an image was taken using the visible channel of the Pyrocam. A fixed pixel to millimeter conversion factor was calculated and applied. The spatial distortion was neglected due to the steep angle of vision.

A general trend of a rising melt pool dimension that levels on a plateau at $15 \mathrm{~mm}$ can be observed. At low weld time, the melt pool dimension appears to be very large. There are two reasons for these measurement artifacts. If the algorithm cannot find a melt pool, the maximum length of the ROI (see green square in Fig. 5) of $36.4 \mathrm{~mm}$ is displayed. The other reason is related to the ignition of the arc. Strong optical arc emissions in the ignition phase interfere with the measurement, which result in deceptive melt pool dimensions. Those measurement artifacts only appear at the beginning of the layer and are not present in the steady phase.

Over the whole progression of the measurement, there is a periodic increase of the weld radius. The reason for that is the meander movement of the welding head in comparison with the direction that the melt pool dimension is measured. Whenever the welding head moves the hatch distance of $3 \mathrm{~mm}$ in travel direction (see Fig. 1), the melt pool dimension increases for a short time by the same amount.
When comparing with the high-speed camera, the Pyrocam measurement seems less reliable in the beginning of the process. Another reason is that very small melt pool dimensions are shaded by the gas nozzle in the Pyrocam set-up, and their accurate measurement is challenging. The Pyrocam set-up has a precision of only $\pm 0.14 \mathrm{~mm}$, while the high-speed camera set-up has a precision of $\pm 0.01 \mathrm{~mm}$.

The automatic analysis algorithm of melt pool dimensions using the Pyrocam is influenced by arc emission deviations. The manual evaluation of the melt pool size using a highspeed camera is not influenced by arc emission deviations since it measures in the range of $800 \pm 20 \mathrm{~nm}$. But the manual evaluation can differ by the subjective impression of the observer on where exactly the fusion line is placed.

The comparison of the melt pool dimensions using both the Pyrocam and the high-speed camera method is shown in Table 4. The challenging measurement of small melt pool dimensions using the Pyrocam is represented by a relative deviation of $14.80 \%$ to the high-speed camera measurement. At bigger melt pool dimensions, the relative deviation is small, and both measurement methods correlate.

In Fig. 7, the melt pool dimensions of the first layer are compared with those of the 9 th layer.

Up to a welding time of $5 \mathrm{~s}$, the melt pool dimensions of the 9th layer are increased like the first layer. However, in comparison with the first layer, the 9th layer shows a bigger melt pool dimension and no points, where the melt pool cannot be found (melt pool dimension $=36.4 \mathrm{~mm}$ ). This suggests that
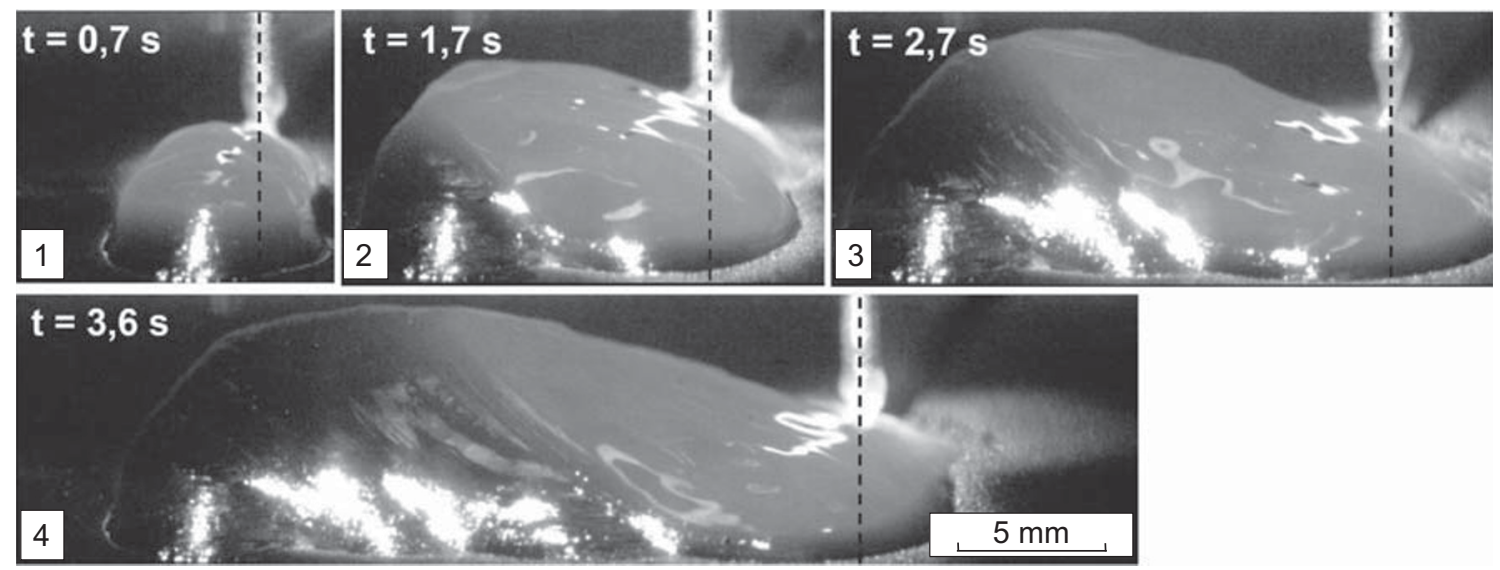

Fig. 4 Melt pool dimension measurement using a high-speed camera at different times 
Table 3 Melt pool dimension in correlation to different weld times

\begin{tabular}{lllll}
\hline Weld time (s) & 0.7 & 1.7 & 2.7 & 3.6 \\
\hline Melt pool dimension high-speed camera (mm) & 3.34 & 8.13 & 10.99 & 12.60 \\
\hline
\end{tabular}

the melt pool is larger, and the Pyrocam set-up has no trouble finding the melt pool of that size.

The measurement artifacts relating to the ignition of the arc are found in the 9th layer as well. The progression of both layers seems similar; however, the melt pool dimension in the 9th layer does not seem to level out on a plateau. It shows a slight decreasing trend. It seems unlikely that the melt pool size in general decreases. One explanation for that decreasing trend could be connected to the measurement method. It is possible that melt pool geometry changes. More material flows in front of the welding head, and therefore, less molten material is present in the trail of the melt pool, where the melt pool dimension is measured.

Fig. 5 Principle of measuring the melt pool size using a Pyrocam

\subsection{Metallography}

A metallographic top view section of the first layer is shown in Fig. 8. It shows the same area of the sample that was previously observed using the high-speed camera. Darker appearing areas in the cross section are artifacts from stitching the image.

The microstructure in the top view section looks homogenous. However, there are some marked areas that stand out. In area $\mathrm{A}$, which is located at the starting point of the weld, the grain size is larger in comparison with the homogenous area in the center of the sample. The reason for the larger grain size is area $\mathrm{A}$ seems to be the higher arc current to ignite the arc as well as a short dwell time to ensure sufficient welding
Fig. 6 Melt pool dimension in correlation to weld time in the first layer
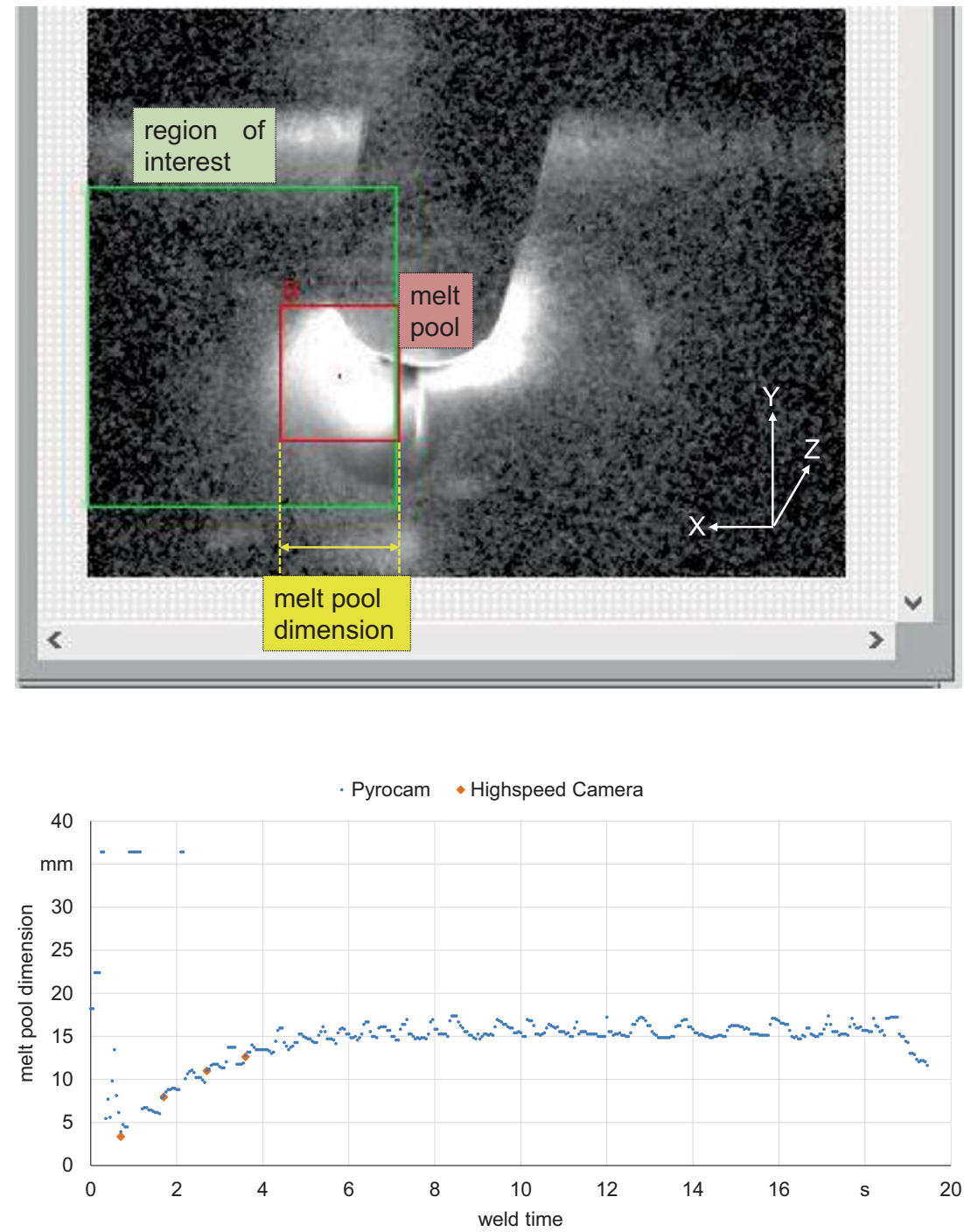
Table 4 Comparison of the melt pool dimensions using both methods

\begin{tabular}{lrrrr}
\hline Weld time (s) & 0.7 & 1.7 & 2.7 & 3.6 \\
\hline Melt pool dimension high-speed camera (mm) & 3.34 & 8.13 & 10.99 & 12.60 \\
Melt pool dimension Pyrocam (mm) & 3.92 & 8.12 & 11.06 & 12.74 \\
Relative deviation (\%) & 14.80 & 0.12 & 0.63 & 1.10 \\
\hline
\end{tabular}

penetration depth. A higher energy input and dwell time result in a higher amount of heat that needs to dissipate and therefore a slower cooling rate.

The morphology in area $\mathrm{B}$, that recurs periodically at the edges of the sample, looks different in comparison with the homogenous area in the center of the sample. While the grain size is similar, a slightly coarser alpha phase within the grains is developed (see Fig. 9 left). The reason for that might be related to the acceleration and deceleration switching between a motion in oscillation into travel direction and back. That actual welding speed at the edge is slower than the nominal welding speed and therefore applying a higher linear energy. In contrast to area A, the energy input in area B is lower, because the arc current stays at the same level. Therefore, no
Fig. 7 Comparison of the melt pool dimensions of different layers measured by the Pyrocam

Fig. 8 Top view section of the first layer with schematic welding head motion
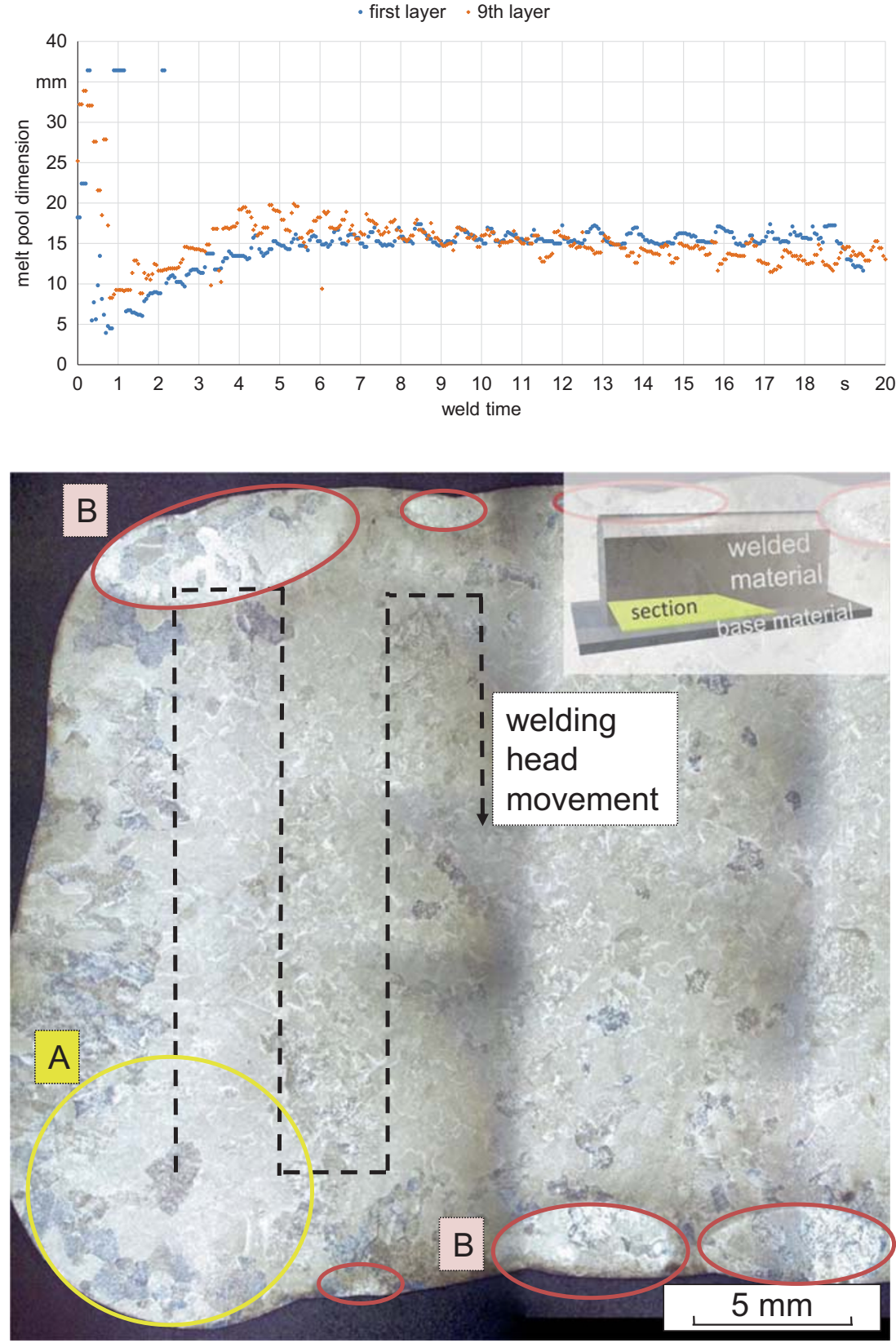
Fig. 9 Magnified view of area B (left) and cross section over multiple layers (right)
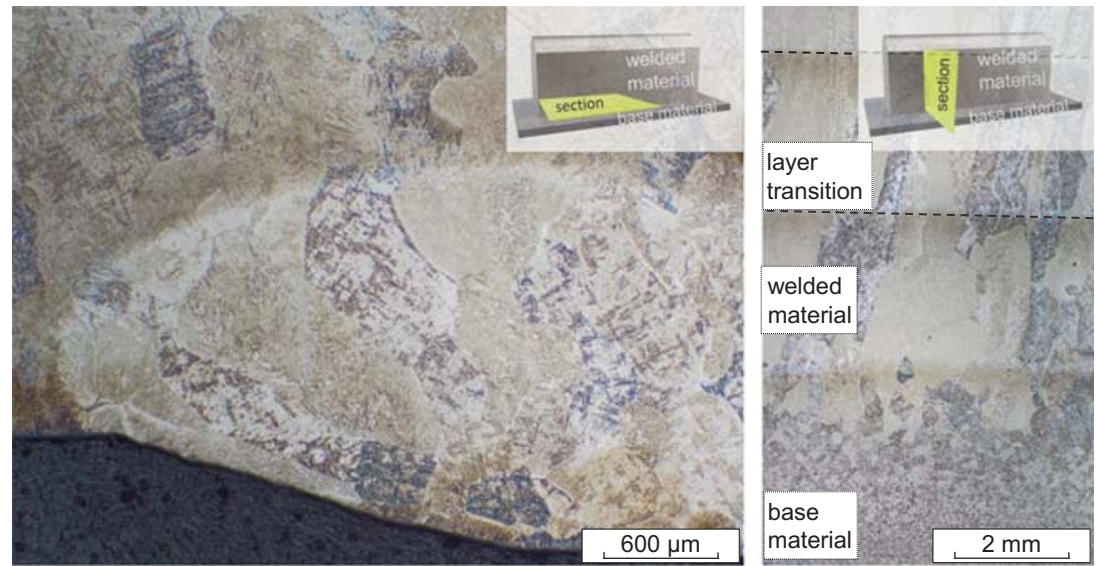

significant grain growth but a slight coarsening of the microstructure is observed.

There seems to be no correlation between the melt pool dimension, that slowly grows over multiple oscillations, and the grain size that developed in homogenous size after one oscillation. That homogenous grain size develops because the solidification follows a moving melt pool, so the preferred growth direction should follow the maximum thermal gradient and therefore change constantly.

In Fig. 9 (right), a metallographic cross section over multiple layers is shown on the right. In contrast to the grain size observed in the top view section, a strong epitaxial grain growth over multiple layers is observed in the cross section, which has been already been observed by Wang et al. [10]. The width of the grains in the cross section seems to correlate with the grain diameter in the top view section.

\section{Conclusions}

It is shown that the evaluation of the melt pool dimension using both a high-speed camera and a high dynamic range two-colored pyrometric camera provide comparable results. In the first layer, the melt pool dimension increases steadily until it levels out on a plateau, while in later layers, the melt pool size seems to decrease slowly. The microstructure is homogenous with slight deviations at the starting point and the edges of the sample. The grain width is smaller in the welding direction, however in the build-up direction the grains grow epitaxially over multiple layers and therefore show a large size. There seems to be no correlation between the melt pool dimension and the grain size. The phenomena of a gradually decreasing melt pool dimension in upper layers are under further investigation.

Funding information Open Access funding provided by Projekt DEAL. The authors received funding from the BMWi (Grant No. 20W1708F). The "BIAS ID" numbers are part of the figures and allow the retraceability of the results with respect to the mandatory documentation required by the funding organization.

Open Access This article is licensed under a Creative Commons Attribution 4.0 International License, which permits use, sharing, adaptation, distribution and reproduction in any medium or format, as long as you give appropriate credit to the original author(s) and the source, provide a link to the Creative Commons licence, and indicate if changes were made. The images or other third party material in this article are included in the article's Creative Commons licence, unless indicated otherwise in a credit line to the material. If material is not included in the article's Creative Commons licence and your intended use is not permitted by statutory regulation or exceeds the permitted use, you will need to obtain permission directly from the copyright holder. To view a copy of this licence, visit http://creativecommons.org/licenses/by/4.0/.

\section{References}

1. Williams SW, Martina F, Addison AC, Ding J, Pardal G, Colegrove $\mathrm{P}$ (2016) Wire + arc additive manufacturing. Mater Sci Technol 32(7):641-647

2. Caballero A, Ding J, Bandari Y, Williams S (2018) Oxidation of Ti6Al-4V during wire and arc additive manufacture. 3D Printing and Additive Manufacturing

3. Bermingham MJ, Thomson-Larkins J, St John DH, Dargusch MS (2018) Sensitivity of Ti-6Al-4V components to oxidation during out of chamber wire + arc additive manufacturing. J Mater Process Technol 258:29-37

4. Hoye N, Li H, Norrish J, Dippenaar R (2011) Post-weld atmospheric contamination of gas tungsten arc deposited welds in commercially pure and Ti-6Al-4V titanium alloys. In: The 12th World Conference on Titanium. pp 1-4

5. Hönnige JR, Colegrove PA, Ahmad B, Fitzpatrick ME, Ganguly S, Lee TL, Williams SW (2018) Residual stress and texture control in Ti-6Al-4V wire + arc additively manufactured intersections by stress relief and rolling. Mater Des 150:193-205

6. Zhang X, Martina F, Ding J, Wang X, Williams SW (2017) Fracture toughness and fatigue crack growth rate properties in wire + arc additive manufactured Ti-6Al-4V. Fatigue Fract Eng Mater Struct 40(5):790-803 
7. Jianjun L, Yaohui L, Yuxin L, Zhe S, Kaibo W, Zhuguo L, Yixiong W, Xu B (2017) Microstructural evolution and mechanical property of Ti-6Al-4V wall deposited by continuous plasma arc additive manufacturing without post heat treatment. J Mech Behav Biomed Mater 69:19-29

8. Xu W, Lui EW, Pateras A, Qian M, Brandt M (2017) In situ tailoring microstructure in additively manufactured Ti-6Al-4V for superior mechanical performance. Acta Mater 125:390-400

9. Neikter M, Åkerfeldt P, Pederson R, Antti M-L, Sandell V (2018) Microstructural characterization and comparison of Ti-6Al-4V manufactured with different additive manufacturing processes. Mater Charact

10. Wang F, Williams S, Colegrove P, Antonysamy A (2013) Microstructure and mechanical properties of wire and arc additive manufactured Ti-6Al-4V. Metall Mater Trans A 44(2):968-977

11. Xu F, Dhokia V, Colegrove P, McAndrew A, Williams S, Henstridge A, Newman ST (2018) Realisation of a multi-sensor framework for process monitoring of the wire arc additive manufacturing in producing Ti-6Al-4V parts. Int J Comput Integr Manuf 31(8):785-798

12. Wu Q, Lu J, Changmeng L, Hongli F, Xuezhi S, Jie F, Shuyuan M (2017) Effect of molten pool size on microstructure and tensile properties of wire arc additive manufacturing of Ti-6Al-4V alloy. Materials (Basel, Switzerland) 10:7
13. Xiong J, Zhang G (2013) Online measurement of bead geometry in GMAW-based additive manufacturing using passive vision. Meas Sci Technol 24:11

14. Pan Z, Ding D, Wu B, Cuiuri D, Li H, Norrish J Arc welding processes for additive manufacturing: a review. Trans Intell Weld Manuf 81:3-24

15. Everton SK, Hirsch M, Stravroulakis P, Leach RK, Clare AT (2016) Review of in-situ process monitoring and in-situ metrology for metal additive manufacturing. Mater Des 95:431-445

16. Xingwang B, Haiou Z, Guilan W (2013) Improving prediction accuracy of thermal analysis for weld-based additive manufacturing by calibrating input parameters using IR imaging. Int J Adv Manuf Technol 69(5-8):1087-1095

17. Köhler H, Thomy C, Vollertsen F (2016) Contact-less temperature measurement and control with applications to laser cladding. Weld World 60(1):1-9

18. Gao XS, Wu CS, Goecke SF, Kuegler H (2017) Effects of process parameters on weld bead defects in oscillating laser-GMA hybrid welding of lap joints. Int J Adv Manuf Technol 93(5-8):1877-1892

Publisher's note Springer Nature remains neutral with regard to jurisdictional claims in published maps and institutional affiliations. 